\title{
Editorial: Perceptual Linguistic Salience: Modeling Causes and Consequences
}

\author{
Alice Blumenthal-Dramé ${ }^{1,2 *}$, Adriana Hanuliková ${ }^{2,3 *}$ and Bernd Kortmann ${ }^{1,2}$ \\ ${ }^{1}$ Department of English, University of Freiburg, Freiburg, Germany, ${ }^{2}$ Freiburg Institute for Advanced Studies, University of \\ Freiburg, Freiburg, Germany, ${ }^{3}$ Department of German, University of Freiburg, Freiburg, Germany
}

Keywords: prediction, language learning, morphology, salience, surprisal, social markers, dialects, language variation and change

\section{Editorial on the Research Topic}

\section{Perceptual Linguistic Salience: Modeling Causes and Consequences}

Recent years have seen an upsurge of interest in the notion of salience in linguistics and related disciplines. The attention literature distinguishes two broad types of perceptual salience (Summerfield and Egner, 2009; Awh et al., 2012). First, a stimulus can be salient-i.e., foremost in one's mind-because it is cognitively preactivated. This type of salience, sometimes referred to as top-down salience, may occur if a stimulus is expected because it is part of a cognitive routine, if it has recently been mentioned, or due to current intentions of the perceiver. Research on salience as

\section{OPEN ACCESS}

Edited and reviewed by: Manuel Carreiras,

Basque Center on Cognition, Brain and Language, Spain

*Correspondence: Alice Blumenthal-Dramé alice.blumenthal@anglistik. uni-freiburg.de

Adriana Hanuliková adriana.hanulikova@germanistik. uni-freiburg.de

Specialty section:

This article was submitted to Language Sciences,

a section of the journal

Frontiers in Psychology

Received: 28 February 2017 Accepted: 06 March 2017 Published: 22 March 2017

Citation:

Blumenthal-Dramé A, Hanulikiková $A$ and Kortmann B (2017) Editorial:

Perceptual Linguistic Salience: Modeling Causes and Consequences.

Front. Psychol. 8:411. doi: 10.3389/fpsyg.2017.00411 a semantic-pragmatic phenomenon has shown that top-down salience can account for systematic preferences in the interpretation of figurative utterances, pronominal antecedents, implicatures, and discursive links (Geeraerts, 2000; Giora, 2003; Chiarcos et al., 2011; Jaszczolt and Allan, 2011).

While in top-down salience, perceivers endogenously direct their attention to a certain stimulus, in the second type of salience, bottom-up salience, it is the stimulus itself which attracts attention. In prototypical cases of bottom-up salience, the stimulus stands out because it is incongruous with a given ground by virtue of intrinsic physical characteristics. But a stimulus may also cause surprise by virtue of deviating from a cognitive ground, e.g., when violating social or probabilistic expectations (Clark, 2013). This has prompted researchers to examine the relationship between expectations and the perceptual salience of linguistic stimuli in new ways (Hanulíková et al., 2012; Rácz, 2012; Hanulíková and Carreiras, 2015; Blumenthal-Dramé, 2016a,b; Roller, 2016; Blumenthal-Dramé et al., 2017), and inspired us to organize a workshop devoted to this particular area.

In October 2014, the Freiburg Institute of Advanced Studies (FRIAS) hosted the workshop "Perceptual linguistic salience: Modeling causes and consequences", organized by the editors of this volume. Bringing together researchers from psycholinguistics, sociolinguistics, neurolinguistics, and cognitive linguistics, the workshop sought to explore the notion of perceptual salience and its explanatory potential for the domains of language processing, variation, and change. Several questions arising from the stimulating discussions were listed in the call for papers for this Research Topic and included the following:

- Which cognitive processes underlie the differential treatment of salient vs. non-salient linguistic percepts?

- How can these processes be accommodated within psycholinguistic models?

- How can the perceptual salience of linguistic forms and variants be operationalized?

- To what extent is salience an intrinsic feature of linguistic forms (e.g., dialectal variants), and to what extent does it result from contextual factors or prior experience with language? 
This volume features nine contributions including five original research articles, one review, and three commentaries that addressed the above questions in very interesting ways. Several contributions discuss which factors or prior experience with language underlie the differential treatment of salient linguistic percepts, and how can they be operationalized and modeled. Jaeger and Weatherholtz argue that sociolinguistic salience can be quantified using computational psycholinguistics. A distinction is made between the initial salience of a novel variant and the cumulative product of experienced exposures to a variant. A variant's salience may be predicted based on its surprisal and frequency. In support of this view, Schmid and Günther propose a unified framework of salience which aims at reconciling seemingly contradictory uses of this notion in the literature: cues are either categorized as salient because they confirm expectations, or because they violate them. Zarcone et al. suggest that an articulated model of salience should take into account attention, affect, and predictability at different levels of processing, and that these dimensions and their interactions can be straightforwardly accommodated within the Predictive Coding framework. Finally, Giraudo and Del Maso present a critical review of so-called decompositional accounts of morphological processing. They argue that the salience of morphemes cannot be reduced to formal factors, and that semantic factors and relationships between holistically represented complex words should also be integrated into models of morphological processing.

Several contributions address the hypothesis that salient items might function as cognitive reference points that structure and give access to certain cognitive domains (e.g., sociolinguistic stereotypes), thereby influencing the perception and categorization of less salient items of the same domain (Rosch, 1975; Langacker, 1993; Hanulíková and Weber, 2012). On the basis of recent theories of enregisterment and exemplar processing, Jensen investigates percepts resulting from sociolinguistic or socio-cognitive salience, more exactly the salience of various morphosyntactic forms in vernacular Tyneside (Northeast England). This study brings to the fore the role of place as strongly shaping both a community's and an individual's linguistic identity and self-representation.

\section{REFERENCES}

Awh, E., Belopolsky, A. V., and Theeuwes, J. (2012). Top-down versus bottom-up attentional control: a failed theoretical dichotomy. Trends Cogn. Sci. 6, 437-443. doi: 10.1016/j.tics.2012.06.010

Blumenthal-Dramé, A. (2016a). "Entrenchment from a psycholinguistic and neurolinguistic perspective," in Entrenchment and the Psychology of Language Learning. How We Reorganize and Adapt Linguistic Knowledge, ed H.-J. Schmid (Boston, MA: APA andWalter de Gruyter), 129-152.

Blumenthal-Dramé, A. (2016b). What corpus-based cognitive linguistics can and cannot expect from neurolinguistics. Cogn. Linguist. 27, 493-505. doi: $10.1515 / \operatorname{cog}-2016-0062$

Blumenthal-Dramé, A., Glauche, V., Bormann, T., Weiller, C., Musso, M., and Kortmann, B. (2017). Frequency and chunking in derived words: a parametric fMRI study. J. Cogn. Neurosci. doi: 10.1162/jocn_a_01120. [Epub ahead of print].
Llamas et al. present metrics for determining the relative salience of phonetic variables in the Scottish-English border zone. This paper substantiates the fact that the choice of features which ultimately become sociolinguistically salient is largely arbitrary. What matters is sufficient agreement among the members of the relevant speech community as to which structural features are considered to function as signals of group membership. Using eye-tracking, Grohe and Weber show for regional dialects of German that salience clearly has an effect on native accent adaptation, but only if objective criteria for salience apply.

The notion of perceptual salience is inextricably linked to issues concerning language acquisition. Cintrón-Valentín and Ellis examine effects of physical salience and attentional biases in the visual and auditory modalities in second language acquisition. Chinese and English native speakers were trained on Latin tense morphology under different types of explicit form-focused instructions, some of which successfully increased learners' attention to less salient morphological features. Rácz et al. use artificial language learning and show that the socialcognitive salience of non-linguistic contexts influences learning of morphological features. Learning is easier with a coherent and interpretable social context (such as gender of the speaker) as opposed to accidental links between the speaker and the construction (such as front-facing vs. side-facing).

Taken together, the papers featured in this volume contribute to our understanding of how the perceptual salience of linguistic forms and variants can be theoretically framed and methodologically operationalized in different areas of linguistic processing.

\section{AUTHOR CONTRIBUTIONS}

All authors listed, have made substantial, direct and intellectual contribution to the work, and approved it for publication.

\section{FUNDING}

Funding for the workshop was provided by the Freiburg Institute for Advanced Studies (FRIAS) at Albert-Ludwigs University in Freiburg, Germany.
Chiarcos, C., Claus, B., and Grabski, M. (2011). Salience: Multidisciplinary Perspectives on its Function in Discourse. Berlin: Walter de Gruyter. doi: 10.1515/9783110241020

Clark, A. (2013). Whatever next? Predictive brains, situated agents, and the future of cognitive science. Behav. Brain Sci. 36, 181-204. doi: $10.1017 /$ S0140525X12000477

Geeraerts, D. (2000). "Salience phenomena in the lexicon: a typology," in Meaning and Cognition: A Multidisciplinary Approach, ed L. Albertazzi (Amsterdam: Benjamins), 79-101. doi: 10.1075/celcr.2.05gee

Giora, R. (2003). On Our Mind: Salience, Context, and Figurative Language. Oxford, UK: Oxford University Press. doi: 10.1093/acprof:oso/9780195136166.001.0001

Hanulíková, A., and Carreiras, M. (2015). Electrophysiology of subject-verb agreement mediated by speaker's gender. Front. Psychol. Cogn. 6:1396. doi: 10.3389/fpsyg.2015.01396

Hanulíková, A., van Alphen, P. M., van Goch, M. M., and Weber, A. (2012). When one person's mistake is another's standard usage: the effect of foreign accent 
on syntactic processing. J. Cogn. Neurosci. 24, 878-887. doi: 10.1162/jocn_a_ 00103

Hanulíková, A., and Weber, A. (2012). Sink positive: linguistic experience with th substitutions influences nonnative word recognition. Atten. Percept. Psychophys. 74, 613-629. doi: 10.3758/s13414-0110259-7

Jaszczolt, K. M., and Allan, K. (2011). Salience and Defaults in Utterance Processing. Berlin: Walter de Gruyter. doi: 10.1515/9783110270679

Langacker, R. W. (1993). Reference-point constructions. Cogn. Linguist. 4, 1-38. doi: $10.1515 / \operatorname{cog} l .1993 .4 .1 .1$

Rácz, P. (2012). Operationalising salience: definite article reduction in the North of England. English Lang. Linguist. 16, 57-79. doi: 10.1017/S1360674311 000281

Roller, K. (2016). Salience in Welsh English Grammar: A Usage-Based Approach. Freiburg: University Library Press. doi: 10.1017/S1360674311 000281
Rosch, E. (1975). Cognitive reference points. Cogn. Psychol. 7, 532-547. doi: 10.1016/0010-0285(75)90021-3

Summerfield, C., and Egner, T. (2009). Expectation (and attention) in visual cognition. Trends Cogn. Sci. 13, 403-409. doi: 10.1016/j.tics.2009.06.003

Conflict of Interest Statement: The authors declare that the research was conducted in the absence of any commercial or financial relationships that could be construed as a potential conflict of interest.

Copyright (C) 2017 Blumenthal-Dramé, Hanuliková and Kortmann. This is an openaccess article distributed under the terms of the Creative Commons Attribution License (CC BY). The use, distribution or reproduction in other forums is permitted, provided the original author(s) or licensor are credited and that the original publication in this journal is cited, in accordance with accepted academic practice. No use, distribution or reproduction is permitted which does not comply with these terms. 